\title{
HEAVY IONS INDUCED DAMAGES IN Ti3SiC2: EFFECT OF IRRADIATION TEMPERATURE
}

J.C. Nappé, Ph. Grosseau, B. Guilhot

École Nationale Supérieure des Mines, SPIN/PMMC, LPMG UMR CNRS 5148

Saint-Étienne, France

F. Audubert, M. Beauvy

CEA, DEN, DEC/SPUA/LTEC

St Paul lez Durance, France

M. Benabdesselam

Université de Nice - Sophia Antipolis, LPMC UMR CNRS 6622

Nice, France

\section{ABSTRACT}

Thanks to their refractoriness, carbides are sensed as fuel coating for the $\mathrm{IV}^{\text {th }}$ generation of reactors. Among those studied, the $\mathrm{Ti}_{3} \mathrm{SiC}_{2}$ ternary compound can be distinguished for its noteworthy mechanical properties: the nanolamellar structure imparts to this material some softness as well as better toughness than other classical carbides such as $\mathrm{SiC}$ or TiC. However, under irradiation, its behaviour is still unknown. In order to understand this behaviour, specimens were irradiated with heavy ions of different energies, then characterised. The choice of energies used allowed separation of the effects of nuclear interactions from those of electronic ones. Thus, AFM, SEM and XRD techniques allowed to note an important spoiling due to nuclear collision whereas electronic interactions would induce the formation of hills and the expansion of the unit cell. Irradiations at higher temperatures allowed to study the effect of temperature on these results.

Key words: $\mathrm{Ti}_{3} \mathrm{SiC}_{2}$, irradiation, heavy ions, AFM, SEM, XRD

\section{INTRODUCTION}

As part of Generation IV International Forum (GIF), new systems are studied, from the point of view of the reactor as well as the fuel cycle. These systems are characterised by an increased security level, better economic competitiveness, and an ability to recycle all the fuel in order to upgrade to a fissionable material and minimize long-lived waste production by transmutation. Among the six systems considered by the GIF, the Gas Fast Reactor (GFR) is studied in France; it is designed to work under helium-pressure and high-temperature (1100-1300 K).

These working conditions led to the selection of non-oxide refractory ceramics as fuel coating. Thus, carbides turn out to be great candidates thanks to their remarkable mechanical and thermal properties. However, their behaviour under irradiation has to be studied in more details.

Among the studied carbides, the ternary $\mathrm{Ti}_{3} \mathrm{SiC}_{2}$ presents some interesting prospects. Indeed, in $1972 \mathrm{Nickl} \mathrm{et} \mathrm{al.}{ }^{1}$ remarked that this material, which was synthesized for the first time by a Viennese group in $1967^{2}$, is abnormally soft for a carbide. Actually, Pampuch et al. ${ }^{3,4}$ and Lis et al. ${ }^{5-7}$ demonstrated that this material is both stiff (Young's modulus of $325 \mathrm{GPa}$ ) and soft (Vickers hardness of $6 \mathrm{GPa}$ ). Moreover, like Goto et al. ${ }^{8}$ some years before, they noted that the hardness of this carbide decreases as the applied load increases; this property led them to qualify $\mathrm{Ti}_{3} \mathrm{SiC}_{2}$ as a "ductile ceramic".

These interesting mechanical properties led to think about $\mathrm{Ti}_{3} \mathrm{SiC}_{2}$ as fuel coating material; actually, its ability to be damage tolerant against mechanical solicitations was expected to be true against irradiations. Nevertheless, besides one paper to be published ${ }^{9}$, no information is available about its behaviour under irradiation. 
Therefore, the aim of this study is a better knowledge of the behaviour under irradiation of $\mathrm{Ti}_{3} \mathrm{SiC}_{2}$, and more particularly the effect of the irradiation temperature.

\section{EXPERIMENTAL}

The studied material is a polycrystalline commercial compound provided by 3-ONE-2 (Voorhees, NJ, USA). Pure bulk of $\mathrm{Ti}_{3} \mathrm{SiC}_{2}$ is quite difficult to synthesize: the as-received material consists of about $80 \% \mathrm{Ti}_{3} \mathrm{SiC}_{2}, 15 \% \mathrm{TiC}$, and $5 \% \mathrm{TiSi}_{2}$ (estimation by X-Ray Diffraction). Figure 1 shows the surface state of the as-polished specimens through Atomic Force Microscopy (AFM); the lower hardness of $\mathrm{Ti}_{3} \mathrm{SiC}_{2}$ compared with the $\mathrm{TiC}$ and $\mathrm{TiSi}_{2}$ phases can be noted.

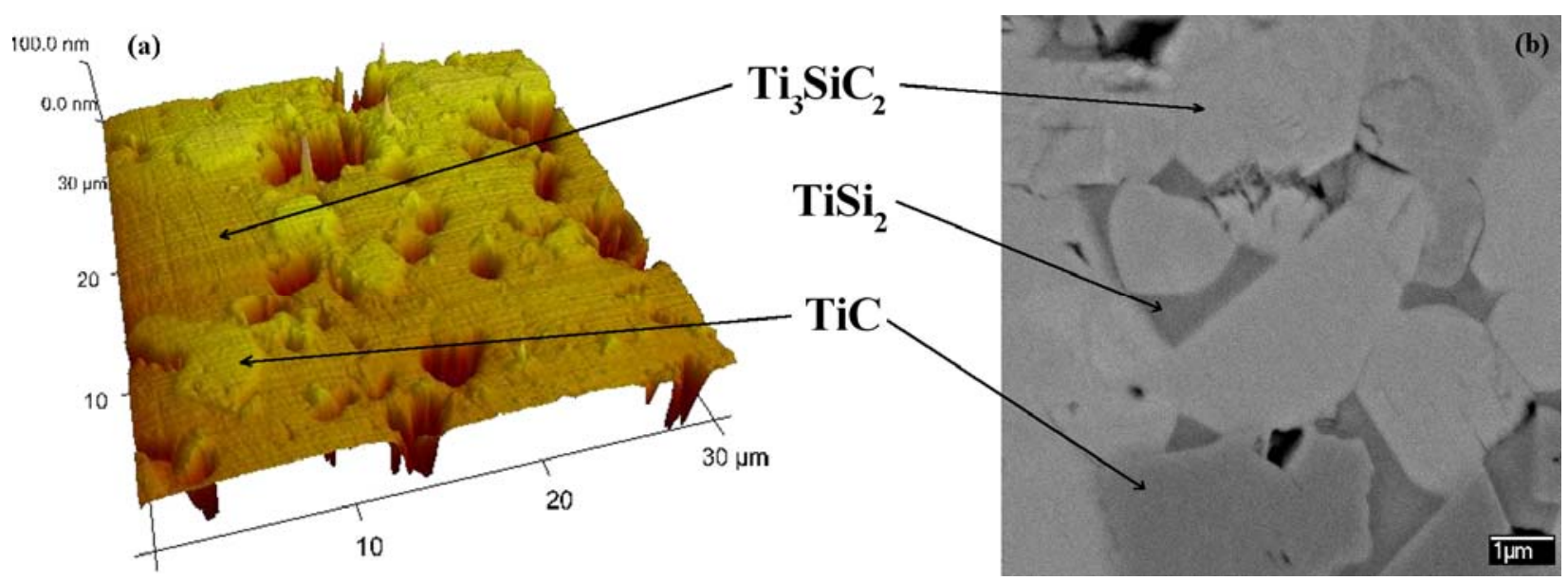

Figure 1. Surface of as-polished $\mathrm{Ti}_{3} \mathrm{SiC}_{2}$ by (a) AFM and (b) back-scattered electrons FEG-SEM.

The as-received specimens were polished with diamond suspensions down to $1 \mu \mathrm{m}$. They were subsequently irradiated with heavy ions. This kind of irradiation aims to simulate the interactions present in reactors (impacts of fission products, recoil atoms of alpha-decays, and neutrons) without the drawback of activating the specimens.

When heavy ions penetrate through a solid, they get decelerated via two different processes, namely, elastic collisions with target nuclei (with nuclear stopping power $S_{n}$ ) and inelastic collisions with target electrons (with electronic stopping power $S_{e}$ ). In order to understand the effects of both nuclear and electronic interactions on $\mathrm{Ti}_{3} \mathrm{SiC}_{2}$, two kinds of irradiation were performed.

The first one, named "high energy irradiation", was made with ions delivered by the IRRSUD accelerator at the GANIL (Caen, France). The energy of these ions reaches several dozen of MeV; for this range of energy, ion path consists in a long zone of electronic interactions (some microns) at the end of which nuclear collisions occur. Thus, studying only the first microns, effects of electronic interactions can be understood. In order to study the effect of electronic stopping power, two different ions were used at the GANIL: $74 \mathrm{MeV} \mathrm{Kr}$ and $92 \mathrm{MeV}$ Xe ions, which respectively lead to a maximum electronic stopping power of 15.6 and $21.3 \mathrm{keV} \mathrm{nm}^{-1}$. Irradiations with $\mathrm{Kr}$ were carried out at room temperature (RT) and $773 \mathrm{~K}$ whereas the ones with Xe were at RT and $573 \mathrm{~K}$.

The second one, called "low energy irradiation", was achieved with the $4 \mathrm{MeV} \mathrm{Au}$ ions of the ARAMIS accelerator at the CSNSM (Orsay, France). This kind of irradiation essentially leads to nuclear collisions. This irradiation was carried out at RT, $773 \mathrm{~K}$ and $1223 \mathrm{~K}$.

Each kind of irradiation was carried out for 4 ion fluences: $10^{12}, 10^{13}, 10^{14}$, and $10^{15} \mathrm{~cm}^{-2}$; the fluence is the number of ion by surface unit. The Table I gives some irradiation parameters determined by the TRIM code ${ }^{10}$. 
Table I. Irradiation parameters

\begin{tabular}{|l|c|c|c|}
\hline Ion & $\mathrm{Au}$ & $\mathrm{Kr}$ & $\mathrm{Xe}$ \\
\hline Mass $(\mathrm{amu})$ & 197 & 86 & 129 \\
\hline Energy $(\mathrm{MeV})$ & 4 & 74 & 92 \\
\hline Projected range $(\mu \mathrm{m})$ & 0.52 & 7.81 & 7.60 \\
\hline Nuclear stopping power $(\mathrm{keV} / \mathrm{nm})$ & 3.29 & 0.07 & 0.16 \\
\hline Electronic stopping power $(\mathrm{keV} / \mathrm{nm})$ & 4.0 & 15.6 & 21.3 \\
\hline
\end{tabular}

To characterise surface modifications to the samples, two microscopic methods were used: Field Emission Gun Scanning Electron Microscopy (FEG-SEM) and AFM. The structure of the irradiated zone was analysed by Low Incidence X-Ray Diffraction (LI-XRD) technique.

\section{RESULTS}

\section{Low Energy Irradiations}

The irradiations performed with $4 \mathrm{MeV}$ Au ions essentially lead to nuclear shocks, which generally cause an important disorder in the materials. As noted elsewhere ${ }^{9}$, this disorder is visible on diffractogrammes from a fluence of $10^{14} \mathrm{~cm}^{-2}$ for irradiations performed at RT, whatever the phase.

The samples irradiated at high temperatures ( $773 \mathrm{~K}$ and $1223 \mathrm{~K}$ ) have not yet been characterized by LI-XRD. Nevertheless, we hope to observe a decrease of disorder due to a greater mobility of atoms making up the samples and to an annealing of the defects by the temperature. This decrease would be a good result if we consider the nominal operating temperatures of the GFR.

In terms of surface conditions, no changes were found before a fluence of $10^{15} \mathrm{~cm}^{-2}$. At room temperature, we noticed a microstructure that we attributed to a sputtering depending on the orientation of cristallites ${ }^{9}$. It is interesting to note that this microstructure is less pronounced during irradiation carried out at $773 \mathrm{~K}$, regaining a microstructure similar to the as-polished specimen for irradiation at $1223 \mathrm{~K}$ (cf. Figure 2).

\section{$200 \mathrm{~nm}$}

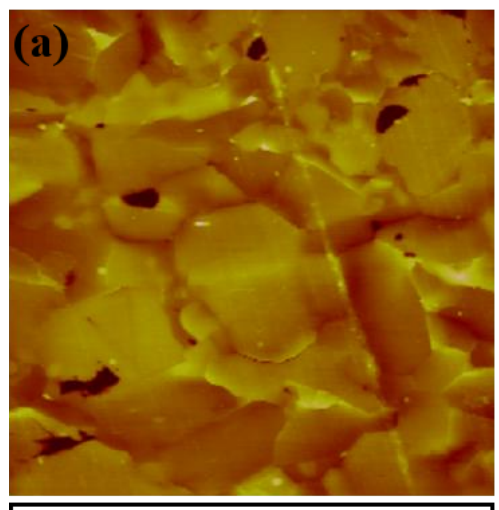

$30 \mu \mathrm{m}$

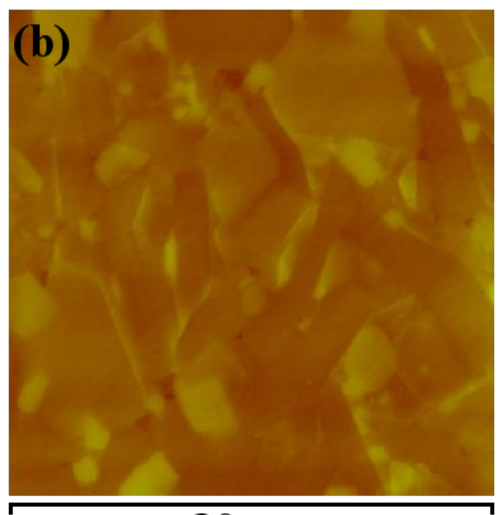

$30 \mu \mathrm{m}$

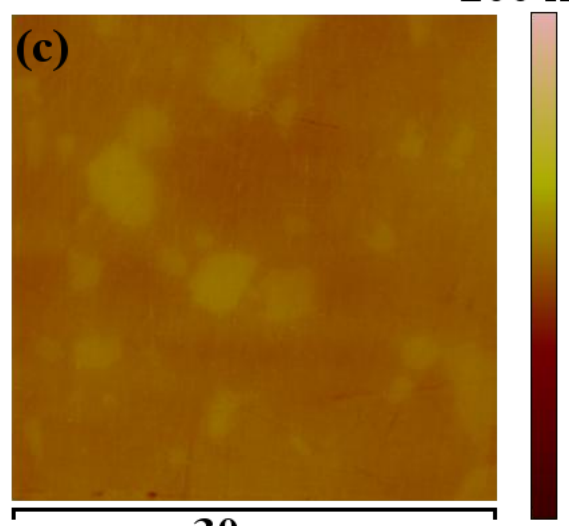

$30 \mu \mathrm{m}$

Figure 2. Surface of $\mathrm{Ti}_{3} \mathrm{SiC}_{2}$ after a $10^{15} \mathrm{~cm}^{-2} 4 \mathrm{MeV}$ Au irradiation at (a) RT, (b) $773 \mathrm{~K}$, and (c) $1223 \mathrm{~K}$.

High Energy Irradiations 
Concerning the high-energy irradiations, we noted by LI-XRD some disorder from $101^{4} \mathrm{~cm}^{-2}$ for $92 \mathrm{MeV}$ Xe irradiation at $\mathrm{RT}$, but only for phase $\mathrm{Ti}_{3} \mathrm{SiC}_{2}$; this disorder is noticeable through a rise of the baseline. Moreover, we noticed an expansion of the hexagonal unit cell of $\mathrm{Ti}_{3} \mathrm{SiC}_{2}$ along $\mathrm{c}$ axis without change in the unit volume ${ }^{9}$. This result is also true for $74 \mathrm{MeV} \mathrm{Kr}$ irradiation at RT.

The temperature has two effects on XRD results. First, a drop-off of the rise of baseline shows a decrease of the disorder as a function of temperature. Second, the unit cell is less expanded for irradiation with $92 \mathrm{MeV}$ Xe at $573 \mathrm{~K}$ to be almost unchanged compared with virgin sample for the irradiation with $74 \mathrm{MeV} \mathrm{Kr}$ at $773 \mathrm{~K}$. Note that whatever the irradiation, the change of the unit cell parameters occurs at constant unit volume (cf. Figure 3).

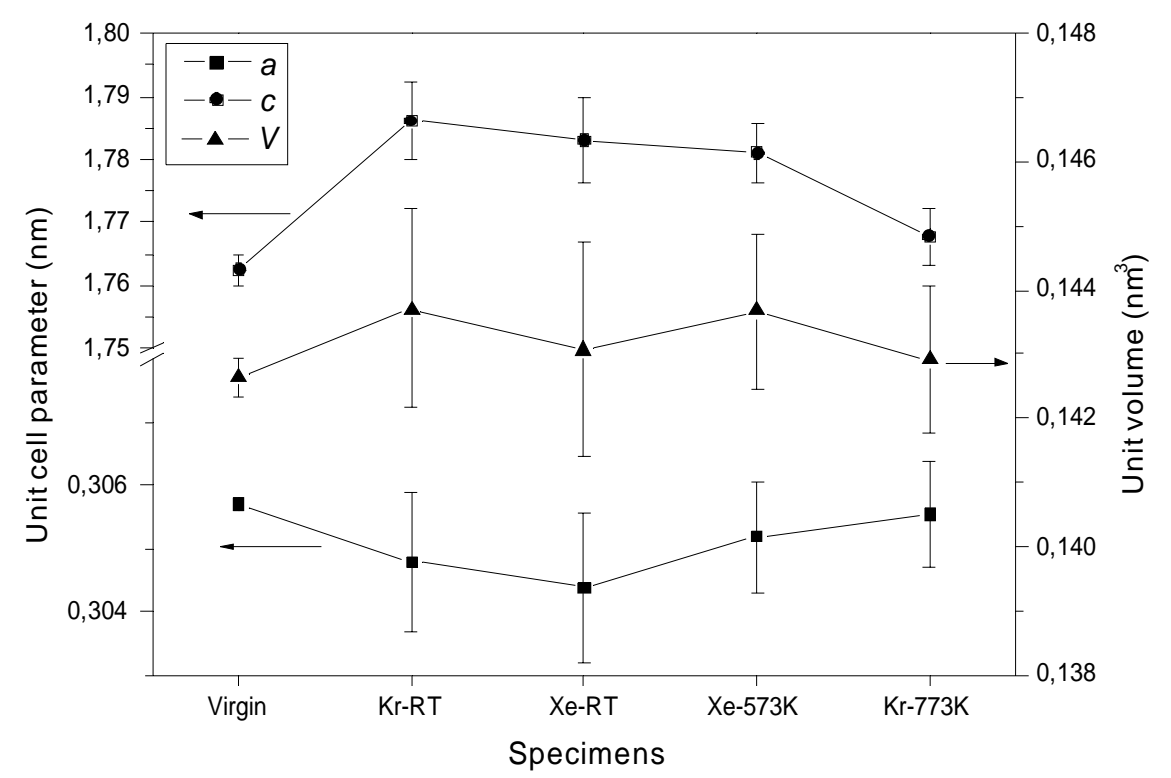

Figure 3. Evolution of Ti3SiC2 unit cell parameters as a function of irradiation parameters for high energy irradiation; lines are only to guide the eye.

With regard to the change in the surface, the first notable point that, unlike irradiation with $92 \mathrm{MeV} \mathrm{Xe}$ at $\mathrm{RT}$, the $74 \mathrm{MeV} \mathrm{Kr}$ irradiation does not cause changes whatever the fluence or temperature. Concerning the $92 \mathrm{MeV}$ Xe irradiation, we underlined the formation of hills on $\mathrm{Ti}_{3} \mathrm{SiC}_{2}$ phase and a revelation of the microstructure due to a different behaviour under irradiation of the secondary phases against $\mathrm{Ti}_{3} \mathrm{SiC}_{2}{ }^{9}$. The difference that is noted for these two high-energy irradiation suggests the existence of an electronic stopping power threshold beyond which there is modification of the surface of the samples.

At $573 \mathrm{~K}$, the surface state of our samples after $92 \mathrm{MeV}$ Xe irradiation is quite similar to irradiations at RT. However, if the revelation of microstructure is always obvious, we can notice that the shape of the hills slightly varies; actually, as shown in Figure 4, they seem larger than for irradiation at RT. This coalescence phenomenon could be compared with the one noted during sintering, suggesting a transfer of matter by temperature. 

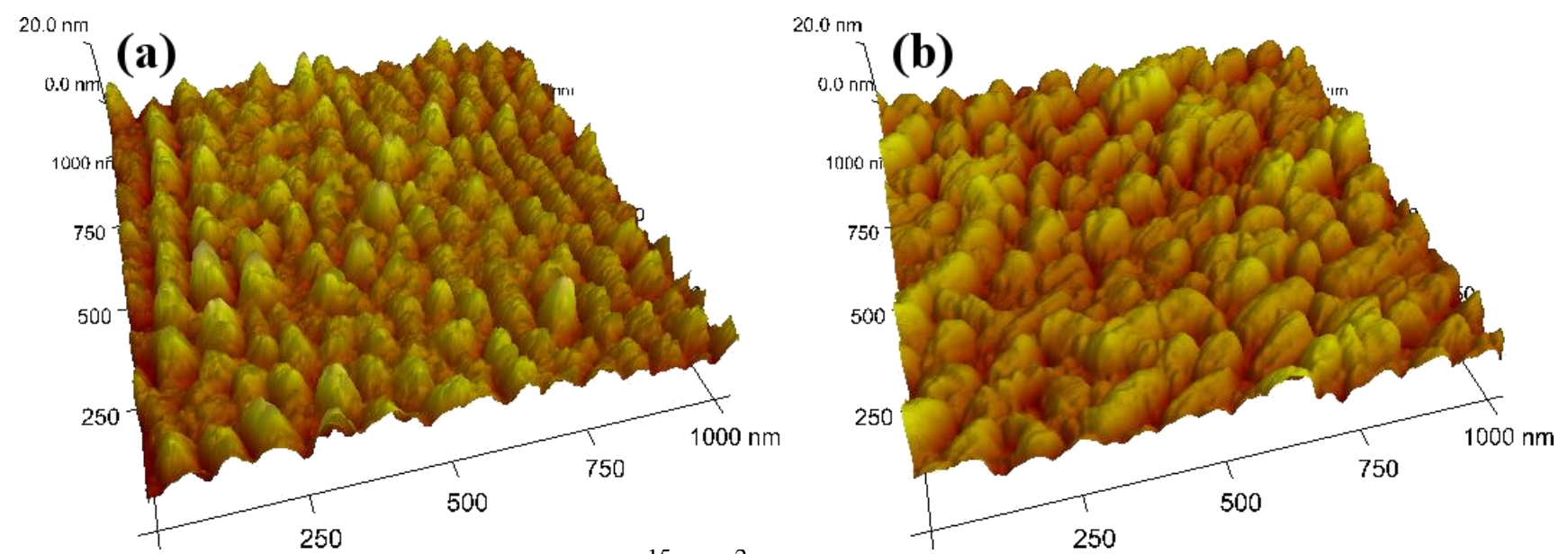

Figure 4. Surface of $\mathrm{Ti}_{3} \mathrm{SiC}_{2}$ after $10^{15} \mathrm{~cm}^{-2} 92 \mathrm{MeV}$ Xe irradiation at (a) RT and (b) $573 \mathrm{~K}$.

\section{CONCLUSION}

In this study, we demonstrated a different behaviour of $\mathrm{Ti}_{3} \mathrm{SiC}_{2}$ under low energy and high energy irradiation. Thus, if the nuclear shocks tend to create an important disorder as well as a sputtering of the surface, the electronic interactions essentially cause an expansion of the unit cell along c axis and the formation of hills beyond an electronic stopping power threshold between 15.6 and $21.3 \mathrm{keV} \mathrm{nm}^{-1}$.

Temperature seems to have two different effects. The first one, as it can be noticed in other carbides like $\mathrm{SiC}^{11-14}$, is an annealing effect of the irradiation defects: decrease of disorder whatever the irradiation, of unit cell expansion due to high energy irradiations, and of the surface changes for the $4 \mathrm{MeV} \mathrm{Au}$ irradiation. The second one is the enlarging of the hills. We understand this effect as a transfer of matter due to both the temperature and the electronic interactions.

\section{ACKNOWLEDGEMENT}

The authors would like to gratefully thank Isabelle Monnet (GANIL) and Lionel Thomé (CSNSM) for their great help during the irradiation experiments. This work was partly supported by the French research group MATINEX.

\section{REFERENCES}

${ }^{1}$ J.J. Nickl, K.K. Schweitzer, P. Luxenberg, Gasphasenabscheidung im Systeme Ti-C-Si, J. LessCommon Metals, 26, 335-353 (1972).

${ }^{2}$ W. Jeitschko, H. Nowotny, Die Kristallstruktur von $\mathrm{Ti}_{3} \mathrm{SiC}_{2}$ - ein neuer Komplexcarbid-Typ, Monatsh. Chem., 98, 329-337 (1967).

${ }^{3}$ R. Pampuch, J. Lis, L. Stobierski, M. Tymkiewicz, Solid Combustion Synthesis of $\mathrm{Ti}_{3} \mathrm{SiC}_{2}, J$. Eur. Ceram. Soc., 5, 283 (1989).

${ }^{4}$ R. Pampuch, J. Lis, J. Piekarczyk, L. Stobierski, $\mathrm{Ti}_{3} \mathrm{SiC}_{2}$-based materials produced by selfpropagating high temperature synthesis and ceramic processing, J. Mater. Synth. Process., 1, 93 (1993).

${ }^{5}$ J. Lis, R. Pampuch, L. Stobierski, Reactions during SHS in a Ti-Si-C system, Int. J. Self-Propag. High-Temp. Synth., 1, 401 (1992).

${ }^{6}$ J. Lis, R. Pampuch, J. Piekarczyk, L. Stobierski, New ceramics based on $\mathrm{Ti}_{3} \mathrm{SiC}_{2}$, Ceram. Int., 19, 219 (1993).

${ }^{7}$ J. Lis, Y. Miyamoto, R. Pampuch, K. Tanihata, $\mathrm{Ti}_{3} \mathrm{SiC}_{2}$-based materials prepared by HIP-SHS techniques, Mater. Lett., 22, 163-168 (1995).

${ }^{8}$ T. Goto, T. Hirai, Chemically vapor-deposited $\mathrm{Ti}_{3} \mathrm{SiC}_{2}$, Mater. Res. Bull., 22, 1195-1201 (1987). 
${ }^{9}$ J.C. Nappé, Ph. Grosseau, F. Audubert, B. Guilhot, M. Beauvy, M. Benabdesselam, I. Monnet, Damages induced by heavy ions in titanium silicon carbide: effects of nuclear and electronic interactions at room temperature, J. Nucl. Mater., in press.

${ }^{10}$ J.F. Ziegler, http://www.srim.org/.

${ }^{11}$ S. Zinkle, L. Snead, Influence of irradiation spectrum and implanted ions on the amorphization of ceramics, Nucl. Instrum. Methods Phys. Res. Sect. B-Beam Interact. Mater. Atoms, 116,92-101 (1996).

${ }^{12}$ W. Weber, N. Yu, L.M. Wang, N.J. Hess, Temperature and dose dependence of ion-beam-induced amorphization in $\alpha$-SiC, J. Nucl. Mater., 244,. 258-265 (1997).

${ }^{13}$ W. Weber, W. Jiang, S. Thevuthasan, Accumulation, dynamic annealing and thermal recovery of ionbeam-induced disorder in silicon carbide, Nucl. Instrum. Methods Phys. Res. Sect. B-Beam Interact. Mater. Atoms, 175-177, 26-30 (2001).

${ }^{14}$ W. Weber, L.M. Wang, N. Yu, N.J. Hess, Structure and properties of ion-beam-modified (6H) silicon carbide, Mater. Sci. Eng., A, 253, 62-70 (1998). 